\title{
Shear Bond Strength of Acetone-Based One-Bottle Adhesive Systems
}

\author{
Guilherme Carpena LOPES ${ }^{1,2}$ \\ Paula C. CARDOSO ${ }^{2}$ \\ Luiz Clovis Cardoso VIEIRA ${ }^{2}$ \\ Luiz N. BARATIERI ${ }^{2}$ \\ Karina RAMPINELLI ${ }^{2}$ \\ Gisele COSTA ${ }^{2}$
}

\author{
${ }^{1}$ Department of Operative Dentistry, University of Southern Santa Catarina (UNISUL), Tubarão, SC, Brazil \\ ${ }^{2}$ Department of Operative Dentistry, Federal University of Santa Catarina (UFSC), Florianópolis, SC, Brazil
}

\begin{abstract}
The aim of this study was to assess the shear bond strength of four acetone-based one-bottle adhesive systems to enamel and dentin, and compare to that of an ethanol-based system used as control. Fifty human molars were bisected mesiodistally and the buccal and lingual surfaces were embedded in acrylic resin using PVC cylinders. The buccal surfaces were ground to obtain flat dentin surfaces, while the lingual surfaces were ground to obtain flat enamel surfaces. All specimens were polished up to 600-grit sandpapers and randomly assigned to 5 groups ( $\mathrm{n}=20$; 10 dentin specimens and 10 enamel specimens), according to the adhesive system used: One-Step (Bisco); Gluma One Bond (Heraeus Kulzer); Solobond M (Voco); TenureQuik w/F (Den-Mat) and OptiBond Solo Plus (Kerr) (control). Each adhesive system was applied according to the manufacturers' instructions. The respective proprietary hybrid composite was applied in a gelatin capsule $(\mathrm{d}=4.3 \mathrm{~mm})$ and light-cured for $40 \mathrm{~s}$. The specimens were tested in shear strength with an Instron machine at a crosshead speed of $5 \mathrm{~mm} / \mathrm{min}$. Bond strengths means were analyzed statistically by one-way ANOVA and Duncan’s post-hoc $(\mathrm{p} \leq 0.05)$. Shear bond strength means $(\mathrm{MPa})( \pm \mathrm{SD})$ to enamel and dentin were: Enamel: One-Step=11.3( \pm 4.9$)$; Gluma One Bond=16.3( \pm 10.1$)$; Solobond $\mathrm{M}=18.9( \pm 4.5)$; TenureQuik w/F=18.7( \pm 4.5$)$ and OptiBond Solo Plus=16.4( \pm 3.9$)$; Dentin: One-Step=6.4( \pm 2.8$)$; Gluma One Bond=3.0( \pm 3.4$)$; Solobond $\mathrm{M}=10.6( \pm 4.9)$; TenureQuik w/F=7.8( \pm 3.9$)$ and OptiBond Solo Plus $=15.1( \pm 8.9)$. In enamel, the adhesive systems had statistically similar bond strengths to each other $(p>0.05)$. However, the ethanol-based system (OptiBond Solo Plus) showed significantly higher bond strength to dentin than the acetone-based systems ( $\mathrm{p} \leq 0.0001)$. In conclusion, the solvent type (acetone or ethanol) had no influence on enamel bond strength, but had great influence on dentin bonding, which should be taken into account when choosing the adhesive system.
\end{abstract}

Key Words: shear bond strength, acid etching, adhesive systems, dentin bonding, enamel bonding.

\section{INTRODUCTION}

Bonding to enamel can be satisfactorily achieved using the acid-etching technique (1). On the other hand, dentin bonding is more difficult due to the wet tubular structure, permeability properties and organic composition of dentinal substrate (2).

For contemporary adhesive systems, dentin bonding requires removal or modification of the smear layer and superficial demineralization by acid etching (2). Although chemical reactions between adhesive systems and dentin have been reported, it is generally accepted that dentin bonding relies primarily on micromechanical interaction similar that of enamel bonding, mediated by the permeation of resin monomers into acid-etched dentin (3). The entanglement of the polymerized adhesive resin with collagen fibrils and residual hydroxyapatite crystals generates an interfacial structure called "resin-dentin interdiffusion zone" or "hybrid layer" (3).

Currently, most studies and developments in dentin bonding are focused on simplification of the

Correspondence: Prof. Dr. Guilherme Carpena Lopes, Rua Laurindo Januário da Silveira, 947, apto 34A, Lagoa da Conceição, $88062-200$ Florianópolis, SC, Brasil. Tel: +55-48-3232-1816. Fax: +55-48-3222-0734. e-mail: guilhermelopes@ccs.ufsc.br 
adhesive process. Several contemporary total-etch adhesive systems combine the primer and bonding agent in one bottle. No mixing of components is required and these simplified or "one-bottle" adhesives are lightcured. Dentin adhesive systems contain high-vapor pressure organic solvents (acetone and ethanol). These chemical agents, known as "water-chases", increase dentin wettability and help replace the water on the acidetched and rinsed dentin surface with hydrophilic resin monomers (4).

In vitro shear bond strength testing is commonly used to quantitatively analyze and rank the performance of adhesive systems on enamel and dentin (5). It has been proved adequate and effective for evaluation and comparison of different adhesive systems and restorative materials.

The aim of this study was to evaluate in vitro the shear bond strength of four acetone-based one-bottle adhesive systems to enamel and dentin, and compare the results to those of an ethanol-based system used as control. The tested hypothesis was that acetone-based and ethanol-based one-bottle systems would yield similar bond strengths to enamel and dentin.

\section{MATERIAL AND METHODS}

Fifty human molars stored in water for up to 3 months were bisected mesiodistally. The buccal and lingual surfaces were embedded in chemically-activated acrylic resin (AcryliMet, South Bay Technology Inc., San Clemente, CA, USA). The 50 buccal surfaces were mechanically ground with water-cooled sandpapers to obtain flat dentin surfaces, while the 50 lingual surfaces were ground to obtain flat enamel surfaces. An area of approximately $5 \mathrm{~mm} \times 5 \mathrm{~mm}$ was demarcated on the surfaces and the specimens were polished with \#240-, \#400- and \#600-grit sandpapers for $30 \mathrm{~s}$. Ten dentin and ten enamel specimens were randomly assigned to 5 groups according to adhesive system used:

One-Step: Dentin/enamel was etched with a 32\% phosphoric acid gel (Uni-Etch; Bisco Dental Products, Schaumburg, IL, USA) for $15 \mathrm{~s}$ and thoroughly rinsed for $5 \mathrm{~s}$. Two coats of One-Step (Bisco) acetone-based one-bottle adhesive system were applied on tooth surface with a disposable brush tip, gently air-dried for $10 \mathrm{~s}$ and light-cured for $10 \mathrm{~s}$.

Gluma One Bond: Dentin/enamel was etched with a 20\% phosphoric acid gel (Gluma CPS Conditioner;
Heraeus Kulzer, Dormagen, Germany) for $20 \mathrm{~s}$ and rinsed for 5 s. Gluma One Bond (Heraeus Kulzer) acetone-based one-bottle adhesive system was richly applied to the entire surface with a disposable brush tip, immediately followed by a second coat. The adhesive sytem was spread over with a gentle air-stream for $5 \mathrm{~s}$ to evaporate the solvent and residual moisture, keeping the air syringe $2 \mathrm{~cm}$ from the surface and light-cured for $20 \mathrm{~s}$.

Solobond M: Dentin/enamel was etched with a $34.5 \%$ phosphoric acid gel (Vococid Gel; Voco, Cuxhaven, Germany) for $15 \mathrm{~s}$ and rinsed for $20 \mathrm{~s}$. One coat of Solobond M (Voco) acetone-based one-bottle adhesive was applied homogeneously to the surface with a disposable brush and left undisturbed for $30 \mathrm{~s}$. Solobond $\mathrm{M}$ was spread over with a faint air jet and lightcured for $20 \mathrm{~s}$.

TenureQuik with fluoride: Dentin/enamel was etched with a $37 \%$ phosphoric acid, medium viscosity etchant (Den-Mat, Santa Maria, CA, USA) for 15 s and rinsed for $10 \mathrm{~s}$. Three consecutive coats of TenureQuik w/F (Den-Mat) acetone-based one-bottle adhesive system were applied to the surface, left undisturbed for $15 \mathrm{~s}$, gently air-dried with oil-free compressed air for 10 $\mathrm{s}$, keeping the air syringe $2 \mathrm{~cm}$ from the surface, and light-cured for $15 \mathrm{~s}$.

OptiBond Solo Plus (control): Dentin/enamel was etched with a 37.5\% phosphoric acid gel (Kerr Gel Etchant; Kerr Co., Orange, CA, USA) for 15 s and rinsed for $10 \mathrm{~s}$. OptiBond Solo Plus (Kerr Co.) ethanolbased adhesive system was brushed continuously onto the surface for $15 \mathrm{~s}$, evaporated with a mild air stream for $3 \mathrm{~s}$ and light-cured for $20 \mathrm{~s}$.

After acid etching and before adhesive application, the surfaces were air-dried with oil-free compressed air from an air syringe during $5 \mathrm{~s}$ for enamel specimens, or to remove water excess and keep surface visibly moist for dentin specimens. A heavy-viscosity micro-hybrid composite (Filtek P-60, 3M/ESPE, St. Paul, MN, USA) was condensed into a No. 5 gelatin capsule with $4.3 \mathrm{~mm}$ in diameter (Torpac Inc, Fairfield, NJ, USA) to fill twothirds of the capsule and was light-cured for $80 \mathrm{~s}$ using UnisX visible light-curing unit (Heraeus Kulzer). Following the application of the adhesive system, an increment of a respective proprietary hybrid composite resin [Aelite (Bisco); Charisma (Heraeus Kulzer), Polofil Supra (Voco), Virtuoso (Den-Mat) and Prodigy (Kerr)] was inserted into the final third of the gelatin capsule and 
the capsule was seated securely against the flat enamel/ dentin surface. Excess material was carefully removed from the capsule periphery and the resin layer was lightcured for $40 \mathrm{~s}$ (20 s at each side of the capsule) using XL 1500 light-curing unit (3M/ESPE). Light intensity, as monitored by a curing radiometer (Demetron/Kerr, Danbury, CT, USA), was over $450 \mathrm{~mW} / \mathrm{cm} 2$ throughout the study.

After a 24-h storage in distilled water, the specimens were submitted to a thermocycling regimen (500 cycles) between water baths at 5 and $55^{\circ} \mathrm{C}$, with a 30-s dwell time in each bath and a 2-s transfer time. Shear bond strength was measured with an Instron Universal Testing Machine (Model 4444, Instron Corporation, Canton, MA, USA), using the Series IX Software System (Instron Corp.) for data recording. A knife-edge-shearing rod running at a crosshead speed of $5 \mathrm{~mm} / \mathrm{min}$ was used to load the specimens until fracture.

Data were analyzed statistically by one-way ANOVA (independent variable: adhesive system; outcome variable: shear bond strength). Duncan's post-hoc test was used to identify statistically significant differences between pairs of means at a confidence level of $95 \%$ for each set of data. Statistical analyses were carried out using the SPSS 10.0 for Windows software package (SPSS Inc., Chicago, IL, USA).

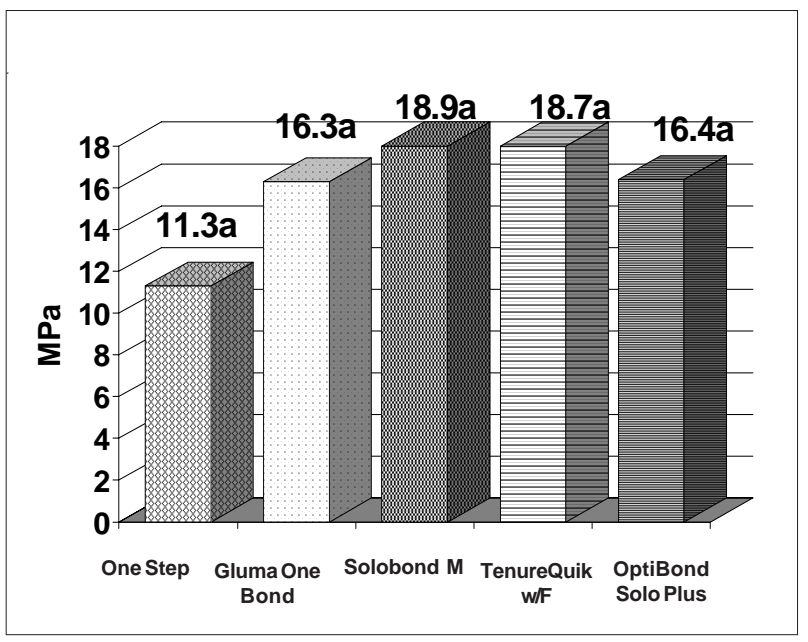

Figure 1. Shear bond strength means (MPa) to enamel. Different letters indicate statistically significant difference at $\mathrm{p}<0.05$. OneStep, Gluma One Bond, Solobond $\mathrm{M}$ and TenureQuik w/F are acetone-based adhesive systems and Optibond Solo Plus (control) is an ethanol-based adhesive system.

\section{RESULTS}

Shear bond strength means are given in Figures 1 and 2.

Shear bond strength to enamel ranged from

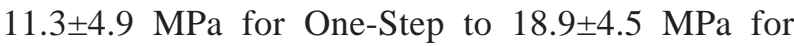
Solobond M (Fig. 1). One-way ANOVA showed no statistically significant difference ( $>0.05$ ) among the enamel specimens . The solvent types of the one-bottle adhesive systems had no influence on enamel bond strength.

Shear bond strength means to dentin ranged

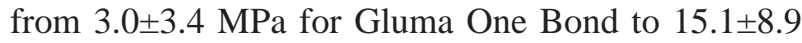
MPa for OptiBond Solo Plus. One-way ANOVA showed that the adhesive systems differed at $\mathrm{p} \leq 0.0001$. Duncan's Post hoc test ranked these differences in three subsets at a confidence level of 95\% (Fig. 2). OptiBond Solo Plus ethanol-based adhesive system differed statistically from the other bonding agents, while Solobond M, OneStep and TenureQuik w/F were ranked in the intermediary Duncan's subset. Although Gluma One Bond presented the lowest dentin bond strength among the adhesive systems, it was not statistically different from One-Step ( $>0.01)$.

Student's t-test revealed higher shear bond strength to enamel than to dentin ( $\mathrm{p} \leq 0.001)$.

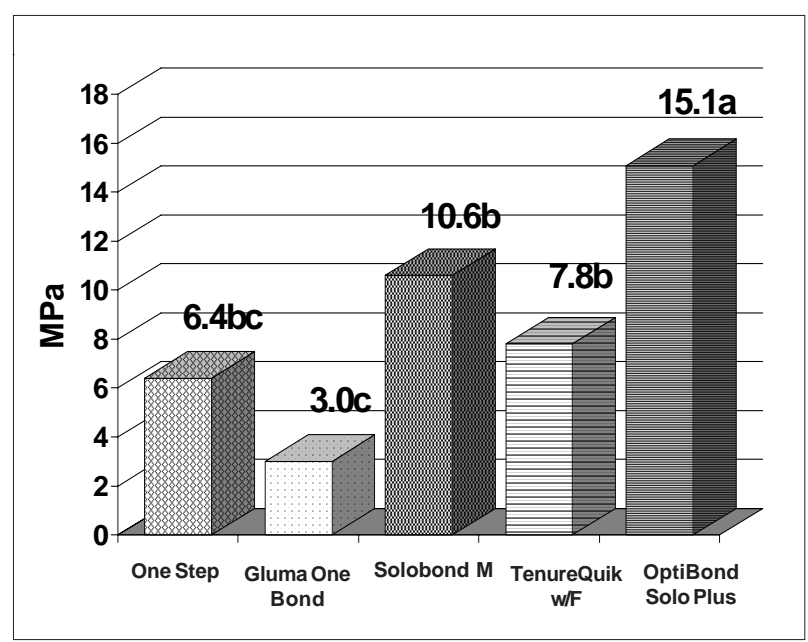

Figure 2. Shear bond strength means (MPa) to dentin. Different letters indicate statistically significant difference at $\mathrm{p}<0.05$. OneStep, Gluma One Bond, Solobond $\mathrm{M}$ and TenureQuik w/F are acetone-based adhesive systems and Optibond Solo Plus (control) is an ethanol-based adhesive system. 


\section{DISCUSSION}

Total-etch one-bottle adhesive systems combine the functions of primer and bonding agent in the same solution. Therefore, less viscous monomers are present diluted in solvents with a high volatile power such as ethanol and acetone. Regarding enamel bonding, this property seems to contribute to a complete interdiffusion of the system all over the etched area (6), resulting in high enamel bond strength (7), even under wet conditions (8). In the present study all total-etch one-bottle adhesive systems yielded similar bond strength to enamel.

The available one-bottle total-etch adhesive systems became popular because they are easy to handle, convenient and more simple to use than multistep adhesive systems, rather than due to a better bonding (9). For hydrophilic bonding systems, dentin bonding is optimized in the presence of high-vapor pressure organic solvents. These solvents facilitate deeper and more complete penetration of monomers into dentin to enhance micromechanical retention (10). It has been reported that to avoid the collapse of the exposed collagen network, adopting a moist bonding protocol is extremely important in acetone-based bonding systems due to the water-chaser effect of acetone (11). On the other hand, the excess of water can dramatically affect acetone-based shear bond strength to dentin (12). Although this study used wet bonding for all systems evaluated, the narrow window of opportunity to achieve adequate dentin bonding with acetone-based systems may explain the fact that all four acetone-based onebottle systems yielded lower shear bond strength means to dentin than the ethanol-based system. These findings are consistent with those of previous studies $(13,14)$. Another possible explanation to the low shear bond strength to dentin reached with acetone-based adhesive systems is its high percentage of acetone (near to $70 \%$ in some systems). This fact may not permit a monomer concentration that is high enough to allow the formation of a uniform film on dentin surface (15). This phenomenon might explain the great variations in bond strengths observed in the literature. For example, studies have reported bond strength means above $20 \mathrm{MPa}$ for One-Step (16), while other studies using similar shear bond strength methodologies reached results around 7.3 MPa (17).

Some of the available one-bottle adhesive systems have filler particles. For this reason, a very favorable flexible intermediate zone is created whereby the interface stress induced by polymerization shrinkage, elasticity module of resins, water sorption and occlusal forces are transmitted and attenuated (18). In a three-dimensional cavity, the formation of this zone is considered very important. However, it has been reported that very viscous bonding agents have greater difficulty to penetrate the etched enamel surface to a depth equal to that of etching (19). Some in vitro studies have shown that filled bonding systems present lower bond strength to enamel $(7,8)$, which seems to be related to the high viscosity of these adhesives (7) that make them unable to penetrate the interprismatic areas as profoundly as the unfilled bonding agents (20). However, this fact apparently depends on product specificities as in the present study the filled adhesive system (Optibond Solo Plus) did not have lower bond strength to enamel than the other systems. Further in vivo studies with total-etch filled adhesive systems are required to investigate whether their higher viscosity would increase long-term marginal infiltration under clinical conditions.

\section{RESUMO}

O objetivo deste estudo foi avaliar a resistência ao cisalhamento de quatro sistemas adesivos de frasco único com solvente acetona e um sistema com solvente etanol em esmalte e à dentina. Cinqüenta molares humanos foram seccionados ao meio no sentido mesiodistal e incluídos com resina acrílica em tubos de PVC. As superfícies vestibulares foram desgastadas até atingir dentina plana, enquanto as superfícies linguais foram desgastadas até atingir esmalte plano. Os espécimes foram polidos até lixa d'água de granulação 600 e divididos aleatoriamente entre os 5 grupos ( $n=20 ; 10$ espécimes de dentina e 10 espécimes de esmalte), de acordo com o sistema adesivo utilizado: One-Step (Bisco); Gluma One Bond (Heraeus Kulzer), Solobond M (Voco), TenureQuik w/F (Den-Mat) and OptiBond Solo Plus (Kerr) (controle). Os adesivos foram aplicados conforme as instruções dos fabricantes. Uma cápsula cilíndrica gelatinosa $(\mathrm{d}=4,5 \mathrm{~mm})$, preenchida com compósito híbrido de cada fabricante foi posicionada sobre a superfície dental e fotopolimerizada durante 40 s. Após 24 h, os corpos-de-prova foram submetidos a ensaios de cisalhamento em uma máquina de ensaios Instron com velocidade de $5 \mathrm{~mm} / \mathrm{min}$. Os dados foram analisados estatisticamente pela ANOVA a um critério e teste de Duncan post hoc $(\mathrm{p} \leq 0.05)$. As médias de resistência ao cisalhamento resistência em esmalte e dentina (MPa) $( \pm \mathrm{SD})$ foram: Esmalte: One-Step $=11,3( \pm 4,9)$; Gluma One Bond $=16,3( \pm 10,1)$; Solobond $M=18,9( \pm 4,5)$; TenureQuik w/ $\mathrm{F}=18,7( \pm 4,5)$ e OptiBond Solo Plus=16,4( $\pm 3,9)$; Dentina: OneStep $=6,4( \pm 2,8)$; Gluma One Bond $=3,0( \pm 3,4)$; Solobond $\mathrm{M}=10,6( \pm 4,9)$; TenureQuik $w / F=7,8( \pm 3,9)$ e OptiBond Solo Plus $=15,1( \pm 8,9)$. Em esmalte, todos os agentes adesivos tiveram resultados estatisticamente semelhantes entre si ( $\mathrm{p}>0.05)$. Entretanto, em dentina, o sistema adesivo a base de etanol 
apresentou maior resistência de união que todos os sistemas a base de acetona $(\mathrm{p} \leq 0.0001)$. O tipo de solvente presente nos sistemas adesivos de frasco único não exerceu influência na sua capacidade de união ao esmalte, mas se mostrou um componente importante na adesão dentinária, o que deve ser levado em conta quando da escolha de um sistema adesivo.

\section{ACKNOWLEDGEMENTS}

The authors acknowledge the manufacturers for supplying the restorative materials used in this study.

\section{REFERENCES}

1. Buonocore MG. A simple method of increasing the adhesion of acrylic filling materials to enamel surfaces. J Dent Res 1955;34:849-853.

2. Lopes GC, Baratieri LN, Andrada MAC, Vieira LCC. Dental adhesion: present state of the art and future perspectives Quintessence Int 2002;33:213-224.

3. Van Meerbeek B, Inokoshi S, Braem M, Lambrechts P, Vanherle G. Morphological aspects of the resin-dentin interdiffusion zone with different dentin adhesive systems. J Dent Res 1992;71:1530-1540.

4. Kanca J. Effect of resin primer solvents and surface wetness on resin composite bond strength to dentin. Am J Dent 1992;5:213-215.

5. Triolo PT Jr, Swift EJ Jr. Shear bond strengths of ten dentin adhesive systems. Dent Mater 1992;8:370-374.

6. Finger WJ, Fritz UB. Laboratory evaluation of onecomponent enamel/dentin bonding agents. Am J Dent 1996;9:206-210

7. Swift Jr. EJ, Perdigão J, Heymann HO. Enamel bond strengths of "one-bottle" adhesives. Pediatr Dent 1998;20:259-262.

8. Swift Jr. EJ, Perdigão J, Heymann HO, Ritter AV. Shear bond strengths of one-bottle adhesives to moist enamel. J Esthetic Dent 1999;11:103-107.
9. Frankenberger R, Kramer N, Petschelt A. Technique sensitivity of dentin bonding: Effect of application mistakes on bond strength and marginal adaptation. Oper Dent 2000;25:324-330.

10. Maciel KT, Carvalho RM, Ringle RD, Preston CD, Russell CM, Pashley DH. The effects of acetone, ethanol, HEMA, and air on the stiffness of human decalcified dentin matrix. J Dent Res 1996;75:1851-1858.

11. Perdigão J, Frankenberger R. Effect of solvent and rewetting time on dentin adhesion. Quintessence Int 2001;32:385-390.

12. Pereira GDS, Paulillo LA, De Goes MF, Dias CT. How wet should dentin be? Comparison of methods to remove excess water during moist bonding. J Adhes Dent 2001;3:257-260.

13. Ritter AV, Heymann HO, Swift EJ Jr, Perdigão J, Rosa BT. Effects of different re-wetting techniques on dentin shear bond strengths. J Esthet Dent 2000;12:85-96.

14. Moll K, Park H, Haller B. Bond strength of adhesive/ composite combinations to dentin involving total- and selfetch adhesives. J Adhes Dent 2002;4:171-180.

15. Perdigão J. An ultra-morphological study of the interaction of adhesive systems with human dentine. Doctoral Thesis, KUL, Van der Poorten, Leuven. 1995.

16. Kanca J. One Step bond strength to enamel and dentin. Am J Dent 1997;10:5-8.

17. Swift EJ, Wilder AD, May KN, Waddell SL. Shear bond strength of one-bottle dentin adhesives using multiple applications. Oper Dent 1997;22:194-199.

18. Van Meerbeek B, Dhem A, Goret-Nicaise M, Braem M., Lambrechts P, Vanherle G. Comparative S.E.M. and T.E.M. examination of ultrastructure of the resin-dentin interdiffusion zone. J Dent Res 1993;72:495-501.

19. Irinoda $\mathrm{Y}$, Matsumura $\mathrm{Y}$, Kito $\mathrm{H}$, Nakano $\mathrm{T}$, Toyama $\mathrm{T}$, Nakagaki H, Tsuchiya T. Effect of sealant viscosity on the penetration of resin into etched human enamel. Oper Dent 2000;25:274-282.

20. Perdigão J, Baratieri LN, Lopes M. Laboratory evaluation and clinical application of a new one-bottle adhesive. J Esthet Dent 1999;11:23-35. 